
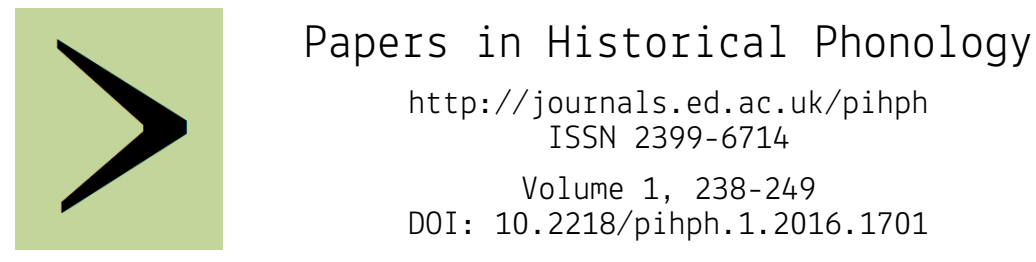

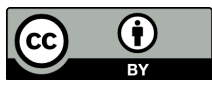

Licensed under a

Creative

Commons 4.0

International

License

\title{
System complexity and (im)possible sound changes
}

\author{
KLAAS T. SEINHORST \\ Amsterdam Center for Language and Communication, \\ University of Amsterdam
}

\begin{abstract}
In the acquisition of phonological patterns, learners tend to considerably reduce the complexity of their input. This learning bias may also constrain the set of possible sound changes, which might be expected to contain only those changes that do not increase the complexity of the system. However, sound change obviously involves more than just pattern learning. This paper investigates the role that inductive biases play by assessing the differences in system complexity of a small number of attested sound changes: the evolution of the obstruent and vowel inventories from old English to Modern English, and the First Germanic Consonant Shift.
\end{abstract}

\section{Introduction}

The idea that typological tendencies in the world's languages may to a large extent be ascribed to learning preferences in the individual learner has received ample attention over the last decade (e.g. Christiansen \& Chater 2008). In this line of research, the rationale is that in the acquisition process, certain hypotheses have larger a priori probabilities than others, and such probability differences are likely to be amplified in successive generations of learners. The (presumable) endpoints of these developments, then, regardless of their starting points, are observed by the linguist as apparent universals.

The reflections of such inductive biases may also be witnessed in diachrony. It is this hypothesis that will be tested in this paper. I will discuss an experiment investigating the interaction between learnability and complexity in simple phoneme inventories (section 2), the results of which show that learners tend to reduce the system complexity of their input; and I will compare the predictions that these experimental results make about diachronic phonology to a small number of attested sound changes (section 3). The conclusion and discussion make up section 4 . 


\section{Theory: system complexity and phonological pattern learning}

I have investigated experimentally how system complexity affects ease of learning in the acquisition of phonological feature combinations (Seinhorst 2016a, 2016b). The data set was designed to resemble a basic plosive inventory: it had one binary feature (such as voice or aspiration) and one ternary feature (place of articulation), yielding a total of six possible feature combinations, or categories. Assuming that a plosive inventory contains between three and six of such combinations, we can distinguish eight structurally different relations between categories (cf. the six different types or 'category structures' of feature combinations in Shepard, Hovland \& Jenkins 1961), see Fig. 1. Black circles indicate categories that are present in the type; white circles indicate categories that are absent. Hence, types I-III describe inventories with three categories, types IV-VI comprise all systems with four categories, an inventory with five categories is of type VII, and type VIII contains all six possible feature combinations. Lines in the vertical planes connect categories with the same place of articulation, and lines in the horizontal planes connect categories that share a voicing/aspiration feature value. All category structures, except for type VIII, have multiple permutations: assuming that the binary feature is [ \pm voice] and the places of articulation are [labial], [alveolar] and [velar], type I in Fig. 1 comprises two possible inventories, namely /p t k/ and /b d g/; twelve inventories are subsumed under type II, such as /p t b/, $/ \mathrm{p} \mathrm{b} \mathrm{d} /$, /t k d/ et cetera.

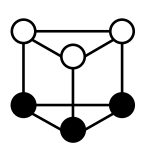

I

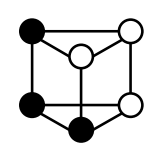

II

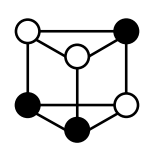

III

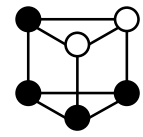

IV

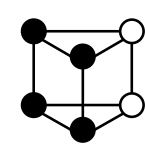

V

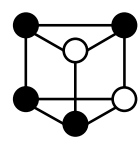

VI

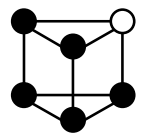

VII

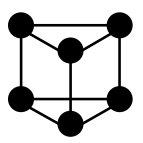

VIII

Figure 1: The eight category structures from Seinhorst (2016a, 2016b).

In the experiments, I used sign language instead of spoken language, in order to avoid an influence of extant phonological knowledge; in analogy with the plosive inventories, each sign could be described as a combination of a binary and a ternary property (thumb opposition and handshape, respectively). Participants were exposed to one of the types from Fig. 1, and were then asked to indicate in which frequency proportions they had seen the six signs (plus two controls). Error score on the task was quantified as the average misestimation per category.

Many participants indicated having seen signs that filled gaps in their input system, i.e. they showed regularizing behaviour (cf. Hudson Kam \& Newport 2005, Reali \& Griffiths 2009). Such errors reduce the 
logical complexity of the set, which is a measure of the compressibility of the representation of the set (Feldman 2000). In this paper, system complexity is equated to the logical complexity of a system, which is operationalized as follows.

Using the feature values [ \pm voice], [labial], [alveolar] and [velar], the three members of the set $/ \mathrm{p} \mathrm{k} \mathrm{d}$ / can be expressed as combinations of [voice] and [labial], [-voice] and [velar], and [+voice] and [alveolar], respectively. In this description we have used six feature values, but there is a shorter way. The value [-voice] occurs twice, and we can actually write it down only once and put the two features it co-occurs with in brackets just like in algebra. If we introduce new members of the set by the ' + symbol and indicate combinations of features by the logical connective ' $\Lambda$ ', we get [-voice $] \wedge([$ labial $]+[$ velar $])+[+$ voice $] \wedge$ [alveolar $]$. Having done this, we do not have any shorter way left anymore: the remaining feature values all occur only once in our description. The logical complexity of our set $/ \mathrm{p} \mathrm{kd} /$, now, is equal to the number of feature values in the shortest possible description of the set: it is 5 .

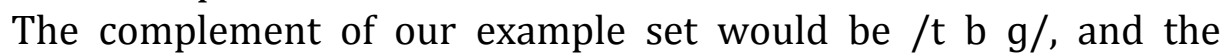
shortest way to describe it is [-voice] \& [alveolar] and [+voice] \& ([labial] and [velar]), so this set also has a complexity of 5 . We can generalize over all possible permutations of a type by indicating our binary feature with a literal, say $a$, and write the values it may take as $a$ and $a^{\prime}$, without being more specific as to which feature value corresponds to which literal; similarly, we can call the ternary feature $b$ and write its possible values as $b, b^{\prime}$ and $b^{\prime \prime}$. The combination of the feature values $a$ and $b$, then, can be written as $a b$. This allows us to express the shortest possible descriptions, also called the minimal formulas, for the eight types and count their logical complexities.

\begin{tabular}{lll}
\hline type & min. formula & complexity \\
\hline \hline I & $a$ & 1 \\
\hline II & $b+a b^{\prime}$ & 3 \\
\hline III & $a\left(b+b^{\prime}\right)+a^{\prime} b^{\prime \prime}$ & 5 \\
\hline IV & $a+a^{\prime} b$ & 3 \\
\hline V & $b+b^{\prime}$ & 2 \\
\hline VI & $b+a b^{\prime}+a^{\prime} b^{\prime \prime}$ & 5 \\
\hline VII & $a+a^{\prime}\left(b+b^{\prime}\right)$ & 4 \\
\hline VIII & $A(=$ all $)$ & 1 \\
\hline
\end{tabular}

Table 1: The minimal formulas and logical complexities of the eight types from Fig. 1.

\footnotetext{
1 ' $\wedge$ ' takes precedence over '+'.
} 
Note that when all possible values of a feature are used in combination with one value of another feature, the former feature is redundant and does not have to be specified in the minimal formula: hence, type I can plainly be described as $a$ instead of $a\left(b+b^{\prime}+b^{\prime \prime}\right)$.

The example sets $/ \mathrm{p} \mathrm{kd} /$ and $/ \mathrm{t} \mathrm{b} \mathrm{g/,} \mathrm{with} \mathrm{three} \mathrm{categories} \mathrm{and} \mathrm{a}$ complexity of 5 , must be of Type III (cf. also Fig. 1). Note that the minimal formulas for both sets can take the form $a\left(b+b^{\prime}\right)+a^{\prime} b^{\prime \prime}$; only the feature values to which the literals correspond are different. In my experiments, logical complexity was a statistically significant predictor of error score, indicating that higher system complexity is negatively correlated with learnability (Seinhorst, 2016b). The complexity of all eight types in the data set together equals 24; in Seinhorst (2016a), 12 people were tested for each type, so the cumulative logical complexity in these 96 people's input was 288. In their output, however, it was only 258 , meaning that they had reduced the complexity of the entire data set by $10.4 \%$. 14 out of 96 participants selected a type that differed from their input; only 2 of them increased the complexity of theirs.

Chater \& Vitányi (2003) and Kirby et al. (2015) argue that compression and simplicity are driving forces in cognition and the evolution of language, and indeed the two cross-linguistically most frequent types of plosive inventory (in P-base: Mielke 2008), nos. I and VIII, are the ones with the lowest complexity. My experimental results suggest that complexity-increasing behaviour is indeed very rare, occurring in only $2 \%$ of all participants, so we may not expect to see it in sound change either: perhaps only those changes are possible that reduce the complexity of the sound system, and those that increase complexity are impossible or very rare (see Honeybone 2016 for an interesting discussion about the notion of possible vs. impossible changes, and which changes may qualify as such.)

\section{Practice: attested phonological sound changes}

Obviously, sound change does not revolve only around learnability and complexity, but perceptual and articulatory pressures play crucial roles too, as well as many other factors. In order to test the hypothesis from the last section, we can look at attested phonological sound changes (meaning those in which some featural representations within the system change, instead of only phonetic properties) and compare the complexities of the systems before and after. I will treat two changes: that of Old English into Middle English into Modern English (§3.1), focusing both on its obstruent inventory (§3.1.1) and vowel system (§3.1.2); and the First Germanic Consonant Shift (§3.2). I will use tables like these: 


\begin{tabular}{l||l|l|l|l|l|l}
\hline & [labial] & \multicolumn{2}{l|}{ [alveolar] } & [velar] \\
\hline \hline [-voice] & $\mathrm{p}$ & $\mathrm{f}$ & $\mathrm{t}$ & $\mathrm{s}$ & $\mathrm{k}$ & $\mathrm{x}$ \\
\hline [+voice] & $\mathrm{b}$ & $\mathrm{v}$ & $\mathrm{d}$ & $\mathrm{z}$ & $\mathrm{g}$ & $\mathrm{d}$ \\
\hline
\end{tabular}

Table 2: Example table.

With the inclusion of fricatives, this example table goes beyond the simple category structures from Fig. 1, but we can establish the complexity of a system in the exact same way as described in $\S 2$.

In the consonant tables in this section, plosives are given in the column left of the dashed line, fricatives are given in the shaded column right of the dashed line. In the vowel tables, short vowels are given in the column left of the dashed line, long vowels in the shaded column to its right. In the notation of the minimal formulas I treat the voicing and length features as binary, and the other features as privative. In general, this allows for more compact descriptions; the only consequence is that we cannot use negation for the place feature, e.g. [-velar] to indicate the set of labials and alveolars. This is a necessary consequence of assuming monovalent features, and I presume that it reflects the way in which language users represent an inventory: language acquisition proceeds on the basis of positive evidence, and speakers do not seem to be aware of what is absent in their language. The features that I assume to be binary may very well be privative too, but in the quantification of system complexity it does not matter how we choose to represent a feature with only two values of interest. For instance, both [-plosive] and its monovalent alternative [fricative] contribute 1 to the complexity count.

It's important to remember that in this approach, it does not suffice to know that /A/ often changes to $/ \mathrm{B} /$, or that in language $\mathrm{X}$ in the Yth century phoneme /C/ turned into /D/; we need to know exactly in the context of which inventory this happened, in order to be able to establish the system complexities before and after. We thus need welldescribed phonological changes, if possible even with an analysis in terms of features.

Also, the system complexity count depends entirely on this analysis, and it does not make any predictions about the direction of a sound change that leaves complexity unaffected: for instance, depending on the inventory in which the change takes place, it would probably not prefer $/ \mathrm{s} />/ \mathrm{h} /$ over $/ \mathrm{h} />/ \mathrm{s} /$, even though we know that the latter is so far unattested (Kümmel 2007). System complexity, being strictly feature-based, also does not take into account that certain phonological feature combinations are deemed impossible, that certain contrasts are 
somehow easier to perceive or produce than others, or that certain contrasts distinguish more minimal pairs than others.

\subsection{Old English to Modern English}

This subsection focuses on the development of Old English into Middle English into Modern English. We will look at both the obstruent systems (§3.1.1) and the vowel inventories (§3.1.2) of these three stages. The source for all tables in this subsection is Lass (2000: 68-71).

\subsubsection{Obstruents}

Old English had the following obstruent system: ${ }^{2}$

\begin{tabular}{|c|c|c|c|c|c|c|}
\hline & [lab.] & [dent.] & [alv.] & [pal.alv] & & \\
\hline [-voi] & $\begin{array}{l:l}\mathrm{p} & \mathrm{f} \\
\end{array}$ & 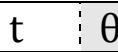 & $\mathrm{s}$ & ts & $\mathrm{k}$ & $\mathrm{x}$ \\
\hline [+voi] & $\mathrm{b}$ & $\mathrm{d}$ & & $\mathrm{d} 3$ & $q$ & \\
\hline
\end{tabular}

Table 3: The obstruents of Old English.

We see a recurrent pattern in this table: for all places of articulation except alveolar, Old English had voiceless and voiced plosives plus a voiceless fricative, and in addition it had /s/. The minimal formula of this system is $([$ plos $]+[-$ voi $] \wedge[$ fric $]) \wedge([$ lab $]+[$ dent $]+[$ pal.alv $]+$ [vel] $)+[-$ voi $] \wedge[$ alv $] \wedge$ [fric], so its complexity is 10 .

The obstruent system of Middle English is given in Table 4:

\begin{tabular}{|c|c|c|c|c|c|c|c|c|}
\hline & \begin{tabular}{|l|l} 
[lab.] \\
\end{tabular} & & & & [alv.] & [pal.al & & \\
\hline [-voi] & $\mathrm{p}$ & $\mathrm{f}$ & $\mathrm{t}$ & $\theta$ & $\mathrm{S}$ & $\mathrm{t} \int: \int$ & $\mathrm{k}$ & $\mathrm{x}$ \\
\hline [+voi] & $\mathrm{b}$ & $\mathrm{V}$ & $\mathrm{d}$ & ð & $\mathrm{Z}$ & $\mathrm{d} 3$ & $g$ & \\
\hline
\end{tabular}

Table 4: The obstruents of Middle English.

Some gaps that still existed in Old English have now been filled, reducing the system complexity to 9 : [lab] $+[$ dent $]+[$ alv $] \wedge[$ fric $]+$ $([$ plos $]+[$ fric $] \wedge[-$ voi $]) \wedge([$ pal.alv $]+[$ vel $])$.

As Middle English turned into Modern English, another gap was filled by $/ 3 /$, and $/ x /$ disappeared, leaving word-initial $/ \mathrm{h} /$ as its only trace and introducing an additional place feature value [glottal]:

\footnotetext{
2 Lass assumes that / $t$ / and / $d$ / were dental, not alveolar; but even if it were the other
} way around, the complexity counts would not change. 


\begin{tabular}{|c|c|c|c|c|c|c|c|c|}
\hline & & & & & [alv.] & [pal.alv] & [velar] & [glottal] \\
\hline [-voi] & $p$ & $f$ & $t$ & $\theta$ & $\mathrm{s}$ & t $\int$ & $\mathrm{k}$ & $\mathrm{h}$ \\
\hline [+voi] & b & $\mathrm{V}$ & $\mathrm{d}$ & ð & $\mathrm{Z}$ & $\begin{array}{l:l} & \\
\text { d3 } & 3\end{array}$ & $\mathrm{~g}$ & \\
\hline
\end{tabular}

Table 5: The obstruents of Modern English.

The minimal formula of this system is [lab] $+[$ dent $]+[$ alv $] \wedge[$ fric $]+$ [pal.alv $]+[$ plos $] \wedge$ [vel] $+[-$ voi $] \wedge$ [glott $] \wedge$ [fric], giving a complexity count of 10: the complexity-reducing regularization in the non-glottal consonants has been counteracted by having unpaired $/ \mathrm{h} /$.

\subsubsection{Vowels}

For the vowels, I will only look at monophthongs. Table 6 lists those of Old English in the analysis of Lass (2000: 68), who does not make a height distinction between near-open /æ/ and open /a:/. This would be a good example of the relevance of the analysis for the complexity count.

\begin{tabular}{|c|c|c|c|c|c|c|}
\hline & \multicolumn{2}{|c|}{ [front, -round] } & \multicolumn{2}{|c|}{ [front, +round] } & \multicolumn{2}{|c|}{ [back] } \\
\hline [close] & $\overline{\mathrm{i}}$ & $\mathrm{i}:$ & $\mathrm{y}$ & y: & $\mathrm{u}$ & $\mathrm{u}:$ \\
\hline [mid] & $\mathrm{e}$ & e: & $\varnothing$ & $\emptyset:$ & 0 & O: \\
\hline [open] & $æ$ & $a:$ & & & & $a:$ \\
\hline
\end{tabular}

Table 6: The monophthongs of Old English.

There are no gaps in the close and mid vowels, only in the open vowels. The minimal formula of this system is [close] $+[$ mid] + [open] $\wedge$ $(([$ front $] \wedge[$-round $]+[$ back $]) \wedge$ [long] $]$, so its complexity is 7 .

The monophthongs of Middle English are presented in Table 7:

\begin{tabular}{l||l:l|l|l}
\hline & [front] & [back] \\
\hline [close] & i & i: & u & u: \\
\hline [close-mid] & e & e: & o & o: \\
\hline [open-mid] & & $\varepsilon:$ & & o: \\
\hline [open] & & a: & & a: \\
\hline
\end{tabular}

Table 7: The monophthongs of Middle English.

All long vowels occur, as well as short close and close-mid short vowels: [+long $]+[-$ long $] \wedge([$ close $]+[$ close-mid $])$, so the complexity count is 4 . 
We now turn to Modern English:

\begin{tabular}{|c|c|c|c|c|c|}
\hline & & & [central & \multicolumn{2}{|c|}{ [back] } \\
\hline [close] & I & i: & & $U$ & $\overline{\mathrm{u}}$ \\
\hline [mid] & $\varepsilon$ & & $3:$ & $\Lambda$ & J: \\
\hline [open] & æ & & & $\mathrm{p}$ & $a:$ \\
\hline
\end{tabular}

Table 8: The monophthongs of Modern English.

Even in Lass' fairly simple representation (which lacks schwa as well as any distinctions between near-close and close or near-open and open vowels), we see a lot more gaps, suggesting that the vowel system has become more complex. Indeed it now has a logical complexity of 7: $[$ front $] \wedge([$ close $]+[$-long $])+[$ central $] \wedge[$ mid $] \wedge[+$ long $]+[$ back $]$.

\subsection{The First Germanic Consonant Shift}

The transition of Proto-Indo-European (PIE) into Proto-Germanic is another excellent testing ground for our hypothesis, because it again provides us with not only an initial and a final stage, but also two intermediate steps: it is essentially three changes wrapped into one.

PIE had a set of plosives with a voicing contrast and an additional aspiration contrast in the voiced stops, plus the alveolar fricative /s/:

\begin{tabular}{|c|c|c|c|c|c|}
\hline & [labial] & [dental] & [alv.] & [velar] & [lab \\
\hline [-voice] & $\mathrm{p}$ & $\mathrm{t}$ & $S$ & $\mathrm{k}$ & $\mathrm{k}^{\mathrm{w}}$ \\
\hline [+voice, -asp] & $\mathrm{b}$ & $\mathrm{d}$ & & $\mathrm{g}$ & $g^{w}$ \\
\hline [+voice, +asp] & $b^{\text {f }}$ & $\mathrm{d}^{\mathrm{h}}$ & & $\mathrm{g}^{\mathrm{f}}$ & $\mathrm{g}^{\mathrm{wh}}$ \\
\hline
\end{tabular}

Table 9: The First Germanic Consonant Shift: stage 1 (initial stage).

The minimal formula for this obstruent system is [plos] $\wedge$ ([lab] + $[$ dent $]+[$ vel $]+[$ lab-vel $])+[$ fric $] \wedge[-$ voi $] \wedge[$ alv $]$, so its complexity is 8. Note that if PIE would not have had /s/ and hence no alveolar place feature, the complexity of its obstruent system would have been 1 . Then again, the existence of a [fricative] feature may have paved the way for the first step of the consonant shift, the spirantization of the voiceless stops: ${ }^{3}$

\footnotetext{
${ }^{3}$ Assuming that it is a set of pull chains, not push chains.
} 


\begin{tabular}{|c|c|c|c|c|c|c|c|}
\hline & [labial] & [denta & [alv.] & \multicolumn{2}{|c|}{ [velar] } & \multicolumn{2}{|c|}{ [lab.-vel.] } \\
\hline [-voice] & $\phi$ & $\theta$ & s & & $\mathrm{X}$ & & $\mathrm{x}^{\mathrm{w}}$ \\
\hline [+voice, -asp] & $\mathrm{b}$ & $\mathrm{d}$ & & $g$ & & $g^{n}$ & \\
\hline [+voice, +asp] & $\mathrm{b}^{\mathrm{h}}$ & $\mathrm{d}^{\mathrm{h}}$ & & $g^{h}$ & & $\mathrm{~g}^{\mathrm{V}}$ & \\
\hline
\end{tabular}

Table 10: The First Germanic Consonant Shift: stage 2 (after step 1).

This system has voiceless fricatives for all its places of articulation, plus the voiced labial, dental, velar and labialized velar plosives: [-voi] $\wedge[$ fric $]+[$ plos $] \wedge[$ [+voi $] \wedge([$ lab $]+[$ dent $]+[$ vel $]+[$ lab-vel $])$. The complexity count remains stable at 8 .

In the second step, the unaspirated voiced stops devoice:

\begin{tabular}{|c|c|c|c|c|c|c|c|c|}
\hline & [labial] & & tal] & [alv.] & & & \multicolumn{2}{|c|}{ [lab.-vel.] } \\
\hline [-voice] & $\mathrm{p}$ & $\mathrm{t}$ & $\theta$ & $\underline{s}$ & $\mathrm{k}$ & $\mathrm{x}$ & $\mathrm{k}^{\mathrm{w}}$ & $\mathrm{x}^{\mathrm{w}}$ \\
\hline [+voice, +asp] & $b^{\text {fh }}$ & $\mathrm{d}^{\mathrm{h}}$ & & & $g^{\text {fh }}$ & & $g^{w h}$ & \\
\hline
\end{tabular}

Table 11: The First Germanic Consonant Shift: stage 3 (after step 2).

We observe a pattern similar to Old English, where for all places of articulation but alveolar there was a set of plosives and a voiceless fricative, plus /s/: the minimal formula is [plos] $\wedge$ ([lab] $+[$ dent $]+[$ vel] $+[$ lab-vel $])+[$ fric $] \wedge[-$ voi $]$. After this step, the complexity decreases to 7.

In the final step, the aspirated stops become unaspirated, rendering the aspiration feature obsolete. As a result of phonemic intervocalic fricative voicing of /s/, Proto-Germanic also gains a category /z/. This gives us the obstruent system in Table 12:

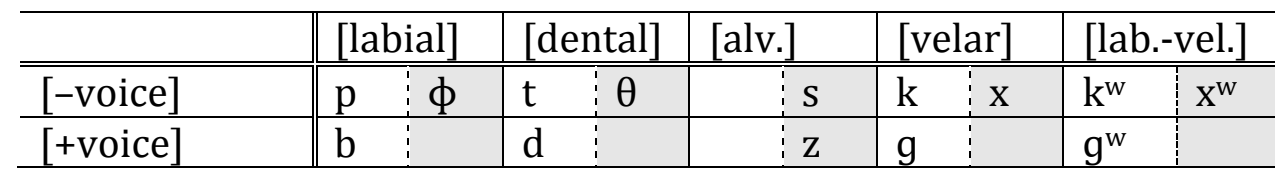

Table 12: The First Germanic Consonant Shift: stage 4 (final, after step 3).

This inventory can be described as [plos $] \wedge([\mathrm{lab}]+[$ dent $]+[$ vel $]+$ $[$ lab-vel $])+[$ fric $] \wedge([-$ voi $]+[$ alv $])$, yielding a system complexity of 8: /z/ is the only voiced fricative in the new system, increasing its complexity. 


\subsection{Evaluation}

Summarizing the complexity counts from the last two subsections, we see that in the development of the English obstruent system, complexity evolved from 10 to 9 to 10; in the English vowel system, it went from 7 to 4 to 7; in the evolution of Proto-Germanic out of Proto-Indo-European, it went from 8 to 8 to 7 to 8 . This means that out of the seven steps that I investigated in this paper, three decreased system complexity, one left it unaffected, and three increased it - in fact, one almost doubled it.

Comparing the initial and final stages of these sound changes, we see that the complexity of the English obstruent system remained stable with complexity 10, whereas the English vowel system and Proto-IndoEuropean have become slightly more complex. In the face of such evidence, we must conclude that the set of possible sound changes is not limited to those that reduce system complexity.

\section{Conclusion and discussion}

This paper aimed to test the hypothesis that sound change strives to decrease the complexity of a sound system, thus improving its learnability. While such complexity-decreasing behaviour has been attested in pattern learning, it was not always seen in the sound changes that were investigated in this paper: only 3 out of the 7 changes made the system less complex, and in the end none of the three sound systems had improved in terms of complexity.

Nevertheless, phonetic pressures are obviously inevitable: consider, for instance, the various strategies that languages have employed to resolve the perceptual confusion between / $/$ / and /g/ (Boersma 1998: 384-386). Each sound change may have found the best possible solution in terms of complexity to deal with those pressures. Let's assume that not too many features can change at once (if that were the case, the voiced aspirated stops in Proto-Indo-European could have turned into voiceless unaspirated fricatives in one go, yielding the same system while obviating the need for all the intermediate steps): even though articulatory and perceptual pressures can counteract learning preferences, the latter may have found the optimal solution insofar as the gradual nature of sound change allows for it.

It is important to keep in mind that the system complexity measure depends entirely on the specifics of our formalization in terms of phonological features; also, it is not sensitive to the fact that some feature combinations are cross-linguistically dispreferred or deemed altogether impossible. For instance, the complexity counts in $\$ 3.1 .2$ would have been much lower if PIE would have had a contrast between dental stops 
and alveolar stops, in which case /s/ would not be as much of an exception; but such a distinction is cross-linguistically not very frequent.

The complexity measure in this article has been logical complexity, as that turned out to correlate with ease of learning statistically significantly better than feature economy in my experiments (Seinhorst, 2016b), and turned out to correlate with of ease of learning in Shepard, Hovland \& Jenkins' (1961) and Feldman's (2000) experiments with non-linguistic feature combinations as well. Interpreting the sound changes from $\S 3$ in terms of feature economy (using a measure similar to Hall's (2007) 'Exploitation'), which we would expect to increase diachronically, we see a slight improvement between the first and final stages of the English obstruent system (from 0.63 to 0.75 to 0.71 , so the last step decreases the economy index), a deterioration in the English vowel inventory (from 0.83 to 0.75 to 0.61 ), and another improvement in the First Germanic Consonant Shift (from 0.43 in stages 1 and 2 to 0.65 in stage 3 and 0.7 in stage 4 ). Future work with an extended sample may tip the scale in the favour of one of both complexity measures - and in general advance our understanding of the role that system complexity plays in sound change.

\section{Comments invited}

PiHPh relies on post-publication review of the papers that it publishes. If you have any comments on this piece, please add them to its comments site. You are encouraged to consult this site after reading the paper, as there may be comments from other readers there, and replies from the author. This paper's site is here:

http://dx.doi.org/10.2218/pihph.1.2016.1701

\section{Acknowledgements}

I'm greatly indebted to Silke Hamann, Paul Boersma, Steve Rapaport and Julian Bradfield for their valuable comments and advice.

\section{Author Contact details}

Klaas Seinhorst

ACLC, University of Amsterdam

Spuistraat 134

1012 VB Amsterdam

The Netherlands

seinhorst@uva.nl 


\section{References}

Boersma, Paul. 1998. Functional Phonology: formalizing the interactions between articulatory and perceptual drives. Amsterdam: University of Amsterdam PhD dissertation.

Chater, Nick \& Paul Vitányi. 2003. Simplicity: a unifying principle in cognitive science? TRENDS in Cognitive Science 7 (1). 19-22.

Christiansen, Morten \& Nick Chater. 2008. Language as shaped by the brain. Behavioral and Brain Sciences 31. 489-558.

Feldman, Jacob. 2000. Minimization of Boolean complexity in human concept learning. Nature 407.630-633.

Hall, Daniel Currie. 2007. The role and representation of contrast in phonological theory. Toronto: University of Toronto PhD dissertation.

Honeybone, Patrick. 2016. Are there impossible changes? $\theta>\mathrm{f}$ but $\mathrm{f} \ngtr \theta$. Papers in Historical Phonology 1. 316-358.

Hudson Kam, Carla \& Elissa Newport. 2005. Regularizing unpredictable variation: the roles of adult and child learners in language formation and change. Language Learning and Development 1 (2). 151-195.

Kirby, Simon, Monica Tamariz, Hannah Cornish \& Kenny Smith. 2015. Compression and communication in the cultural evolution of linguistic structure. Cognition 141. 87-102.

Kümmel, Martin Joachim. 2007. Konsonantenwandel: Bausteine zu einer Typologie des Lautwandels und ihre Konsequenzen für die vergleichende Rekonstruktion. Wiesbaden: Reichert Verlag.

Lass, Roger. 2000. Phonology and morphology. In Lass, Roger (ed.), The Cambridge History of the English Language, Volume 3: 1746-1776, 56-186. Cambridge: Cambridge University Press.

Mielke, Jeff. 2008. The emergence of distinctive features. Oxford: Oxford University Press.

Reali, Florencia \& Thomas Griffiths. 2009. The evolution of frequency distributions: relating regularization to inductive biases through iterated learning. Cognition 111. 317-328.

Seinhorst, Klaas T. 2016a. Mind the gap: inductive biases in phonological feature learning. In: Roberts, Séan et al. (eds.), The Evolution of Language: Proceedings of the 11th International Conference.

Seinhorst, Klaas T. 2016b. Feature economy vs. logical complexity in phonological pattern learning. Language Sciences. dx.doi.org/ 10.1016/j.langsci.2016.10.002

Shepard, Roger, Carl Hovland \& Herbert Jenkins. 1961. Learning and memorization of classifications. Psychological Monographs 75 (13). 